\title{
Clinical And Radiological Evaluation of Plantar Fasciitis
}

\author{
Dr.Chandini Kovvuri ${ }^{1}$, Dr.Sandesh Reddy Yaratapalli ${ }^{2}$, Prof.Seshu Lakshmi.B ${ }^{3}$ \\ ${ }^{1}$ Department of Radiodiagnosis, NRI medical college, India) \\ ${ }^{2}$ Department of Orthopaedics, Sri ramachandra University, India)
}

\begin{abstract}
To compare the clinical and radiological evaluation of plantar fasciitis. This is a prospective cohort study and a total of 110 patients were studied. All patients were diagnosed as plantar fasciitis by clinical and radiological evaluation. Patients were assessed functionally using VAS and FAOS scores and radiologically by Ultrasound of the foot and X-ray lateral view of the foot. On evaluation VAS and FAOS scores were 6.85 and 32.8 respectively. X-ray showed a calcaneal spur on lateral view. Similarly ultrasound evaluation showed thickened plantar fascia and edema around the origin of the tissue.
\end{abstract}

Key words: foot and ankle outcome score(FAOS), plantar fasciitis, ultrasound, visual analog pain score(VAS)

\section{Introduction}

Plantar fasciitis is one of the most common cause of heel pain. It is thought to result from chronic overload and is characterized by pain at the calcaneal origin of the plantar fascia, exacerbated by weight bearing after prolonged periods of rest.

Diagnosis of plantar fasciitis warrants a thorough clinical history and physical examination. It usually presents with a sharp morning heel pain and first-step pain that improves with normal use during day and worsens with heavy use.

Physical examination is marked by localized tenderness at the medial tubercle of the calcaneus, loss of ankle dorsiflexion due to gastrocnemius muscle or Achilles tendon tightness, and in more severe cases, increased heel discomfort with passive toe dorsiflexion. Radiological evaluation by $\mathrm{x}$ ray and ultrasound heel have helped in the confirmation of diagnosis.

\section{Aim Of The Study}

To compare the clinical and radiological evaluation of plantar fasciitis.

\section{Materials And Methods:}

Study was done between may 2014 - december 2016. This is a prospective study and a total of 110 patients were studied. All patients were diagnosed as plantar fasciitis by clinical and radiological evaluation.

4.1: Visual Analog Score (Vas):

IV. Results

Patients had a VAS of 6.85 to 6.95 on an average.

4.2: Foot And Ankle Outcome Score (Faos):

FAOS on an average was about 32.8 to 34.1 respectively.

\section{3: Sonographic Evaluation:}

On sonographic evaluation, the average thickness of planatar fascia at its origin was about $0.7 \mathrm{cms}$ on an average. There was edema noted around the plantar fascia

\section{4: $x$ ray evaluation:}

x-ray lateral view of the foot showed a calcaneal spur in almost all of the patients with chronic plantar fasciitis.

\section{Discussion}

Chronic heel pain is a difficult condition to treat. Traditionally it has been treated by Physiotherapy, use of soft heel foot wear and local Corticosteroid injections. It is well known that pain does not subside quickly, but can persist for several weeks and this results in significant disability.

Researchers like Lee et al, Barrett et al, MartinJ.O'malley et al have done studies using ultrasound and $\mathrm{x}$ ray as guide for diagnosis of plantar fasciitis.

Augustus D. Mazzocca et $\mathbf{a l}^{12}$. in 2012 (JBJS) also adopted this method for the diagnosis of chronic plantar fasciitis. 
Studies by Mark W. Scioli MD ${ }^{3}$, Joost $\mathbf{C}$ Peerbooms et $\mathbf{a l}^{6}$. also found this method to be very effective.

Earlier Lee et $\mathbf{a l}^{16}$. conducted prospective randomised, controlled study of 64 patients for a period of 6 months by comparing PRP with corticosteroid injection. The authors advocated clinical and radiological evaluation for the diagnosis..

In a separate studies by Barrett et al ${ }^{17}$ and Martin J.O'malley et al ${ }^{7}$ similar results were found.

\section{Figures}

Case 1:

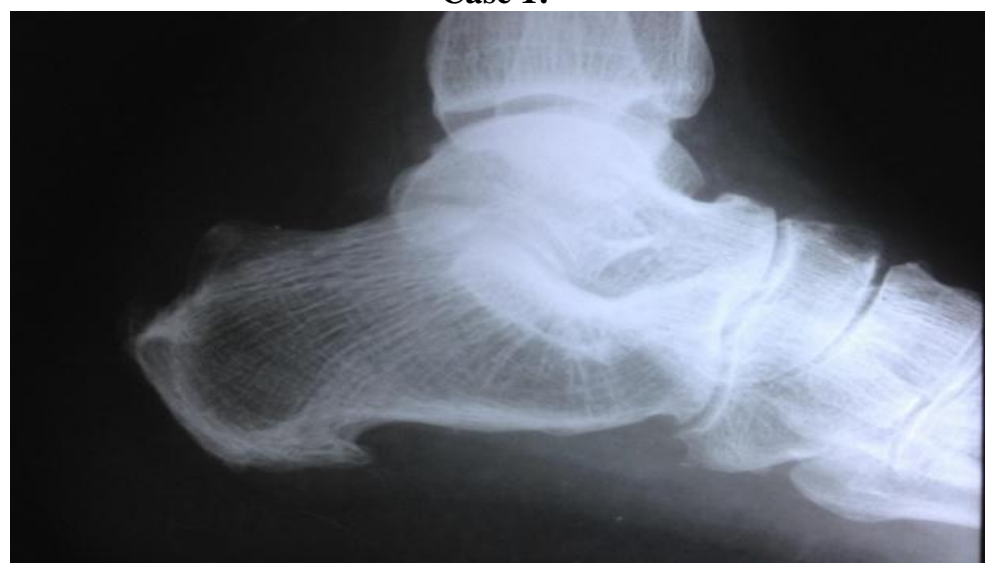

Figure 1.1: lateral radiograph of foot showing a calcaneal spur

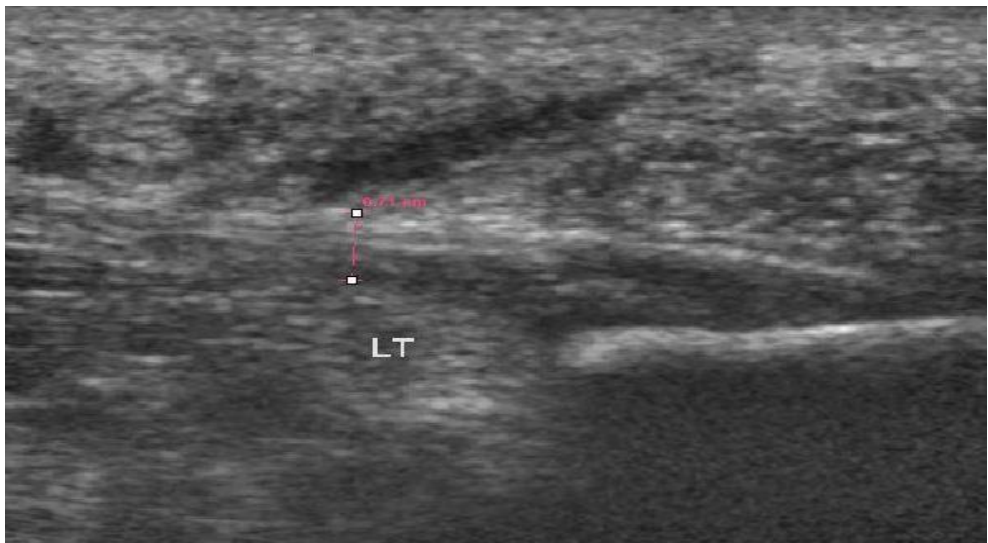

Figure 1.2: pre-injection USG of left heel showing thickened plantar fascia $(0.71 \mathrm{~cm})$ and surrounding edema

\section{Case 2:}

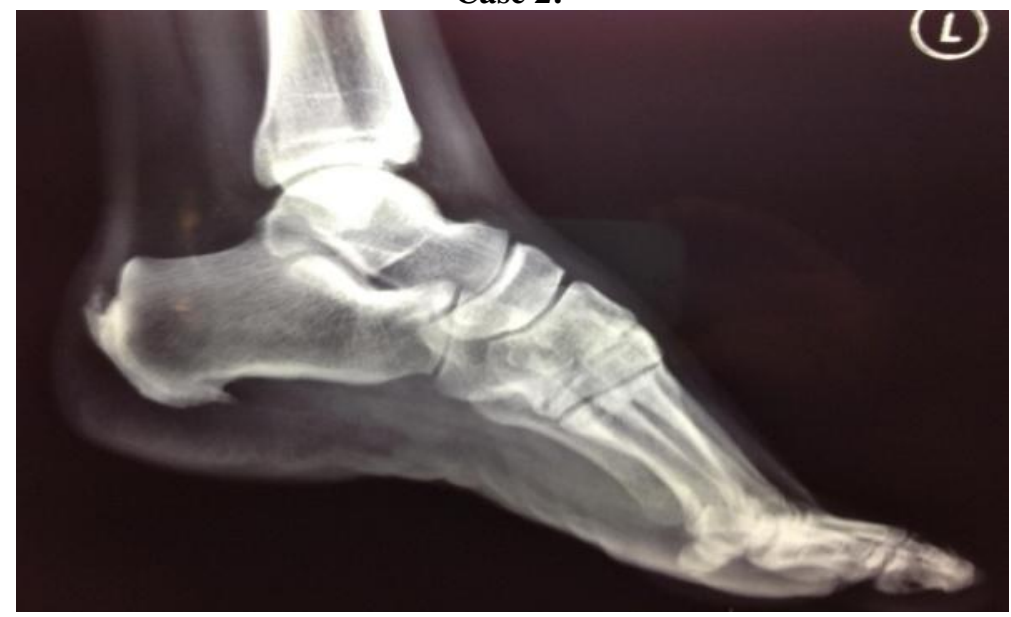

Figure 2.1: $x$ ray left foot showing a calcaneal spur 


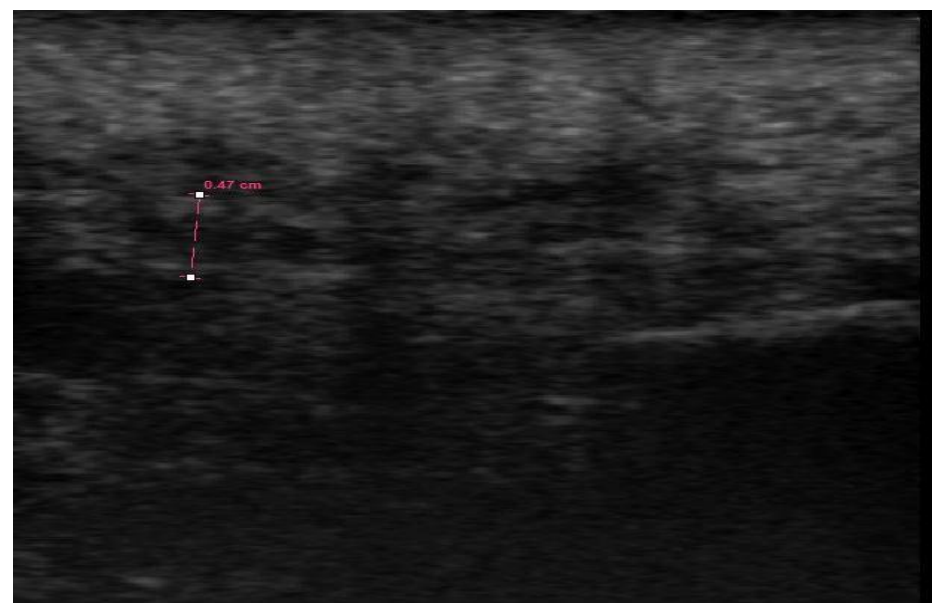

Figure 2.2: pre-injection USG of left heel showing thickened plantar fascia $(0.47 \mathrm{~cm})$ and surrounding edema

\section{Conclusion}

Chronic heel pain is a difficult condition to treat and takes a long time to resolve. Our study has shown that a thorough clinical and radiological evaluation play an important role in the diagnosis of plantar fasciitis. Both clinical and radiological evaluation are equally important in the diagnosis.

\section{References}

[1]. Tiwari M, Bhargava R. Platelet rich plasma therapy: A comparative effective therapy with promising results in plantar fasciitis. Journal of Clinical Orthopaedics and Trauma. 2013;4(1):31-5.

[2]. Thing J, Maruthappu M, Rogers J. Diagnosis and management of plantar fasciitis in primary care. British Journal of General Practice. 2012;62(601):443-4

[3]. Scioli MW. Platelet-rich plasma injection for proximal plantar fasciitis. Techniques in Foot \& Ankle Surgery. 2011;10(1):7-10.

[4]. Schwartz EN, Su J. Plantar Fasciitis: A Concise Review. The Permanente Journal. 2014;18(1):e105.

[5]. Sabir N, Demirlenk S, Yagci B, Karabulut N, Cubukcu S. Clinical utility of sonography in diagnosing plantar fasciitis. Journal of ultrasound in medicine. 2005;24(8):1041-8.

[6]. Peerbooms JC, van Laar W, Faber F, Schuller HM, van der Hoeven H, Gosens T. Use of platelet rich plasma to treat plantar fasciitis: design of a multi centre randomized controlled trial. BMC Musculoskelet Disord. 2010;11:69.

[7]. O’Malley MJ, Vosseller JT, Gu Y. Successful Use of Platelet-Rich Plasma for Chronic Plantar Fasciitis. HSS Journal®. 2013;9(2):129-33.

[8]. Monto RR. Platelet-Rich Plasma Efficacy Versus Corticosteroid Injection Treatment for Chronic Severe Plantar Fasciitis. Foot \& Ankle International. 2014:35(4):313-8.

[9]. Monto RR. Platelet-rich plasma and plantar fasciitis. Sports medicine and arthroscopy review. 2013;21(4):220-4.

[10]. Monto R. Platelet-rich plasma is more effective than cortisone for chronic plantar fasciitis. Journal of Bone \& Joint Surgery, British Volume. 2012;94(SUPP XXXIX):55-.

[11]. McMillan AM, Landorf KB, Gilheany MF, Bird AR, Morrow AD, Menz HB. Ultrasound guided corticosteroid injection for plantar fasciitis: randomised controlled trial. BMJ: British Medical Journal. 2012;344.

[12]. Mazzocca AD, McCarthy MBR, Chowaniec DM, Cote MP, Romeo AA, Bradley JP, et al. Platelet-rich plasma differs according to preparation method and human variability. The Journal of Bone \& Joint Surgery. 2012;94(4):308-16.

[13]. Martinelli N, Marinozzi A, Carnì S, Trovato U, Bianchi A, Denaro V. Platelet-rich plasma injections for chronic plantar fasciitis. International orthopaedics. 2013;37(5):839-42.

[14]. Cutts S, Obi N, Pasapula C, Chan W. Plantar fasciitis. Annals of the Royal College of Surgeons of England. 2012;94(8):539.

[15]. Cardinal E, Chhem RK, Beauregard CG, Aubin B, Pelletier M. Plantar fasciitis: sonographic evaluation. Radiology. 1996;201(1):257-9.

[16]. Lee TG, Ahmad TS. Intralesional autologous blood injection compared to corticosteroid injection for treatment of chronic plantar fasciitis. A prospective, randomized, controlled trial. Foot Ankle Int. 2007;28(9):984-990.

[17]. Barret S, Erredge S. Growth factors for chronic plantar fasciitis. Podiatry Today. 2004;17:37-42.

[18]. Aziza Sayed Omar, Maha Emad Ibrahim, Amal Sayed Ahmed, Mahmoud Said. Local injection of PRP and corticosteroid in treatment of lateral epicondylitis and plantar fasciitis. Randomized clinical trial. The Egyptian Rheumatologist Journal. 2012;34:4349.

[19]. Eugene G. McNally, Shilpa Shetty. Plantar Fascia: Imaging Diagnosis and Guided Treatment. Seminar in musculoskeletal radiology. 2010;14(3):334-343

[20]. Michelle Wright. Plantar Fasciitis, EMIS, patient.co.uk. peer review article. 2012. 